\title{
Prevalence of diabetes, prediabetes, awareness, treatment and control among people 35 years and up
}

Seyed Morteza Shamshirgaran

Neyshabur University of Medical Sciences

Zohreh Ghorbani

Tabriz University of Medical Sciences

Farzad Najafipour

Tabriz University of Medical Sciences

Parvin Sarbakhsh

Tabriz University of Medical Sciences

Nayyereh Aminisani ( $\square$ aminisani_n@hotmail.com )

Tabriz University of Medical Sciences https://orcid.org/0000-0001-9947-2064

Research article

Keywords: Diabetes Mellitus, Prediabetes, Prevalence, Awareness, PERSEAN Cohort Study, Azar cohort

Posted Date: May 1st, 2020

DOI: https://doi.org/10.21203/rs.3.rs-22638/v1

License: @ (1) This work is licensed under a Creative Commons Attribution 4.0 International License. Read Full License 


\section{Abstract}

Background Despite the current endeavors in the prevention and treatment of diabetes, it is, still, one of the leading causes of mortality, morbidity, and health system costs worldwide. The aim of this study was to determine the prevalence of pre-/diabetes, awareness, treatment, and control of diabetes and its correlates among people participating in the pilot phase of the Azar cohort study in the Northwest of Iran.

Methods A total of 1038 adults aged 35 years and older in Khamene city, East Azerbaijan province, Northwest of Iran, were recruited for the pilot phase of Azar cohort; a province-level of a nationwide PERSIAN cohort study. A comprehensive questionnaire including sociodemographic and clinical information was completed, and biological samples were collected. The quantities of $\mathrm{HbA}_{1} \mathrm{C}$ and $\mathrm{FBS}$ were adopted as benchmarks for assessing the status of subjects about having diabetes and pre-diabetes. All analyses were performed using STATA (version 14), the statistical software.

Results The overall prevalence of diabetes and pre-diabetes was $18.2 \%$ and $34.8 \%$, respectively. The result of the multivariate regression model showed, females had a better awareness (2.00 (Cl: 0.94-4.26)), and their reception of diabetes' medicine was higher: 2.57 (Cl: 1.255.29). Having at least one comorbid condition was associated with an increased awareness of diabetes (3.13 (Cl: 1.47-6.66)); in addition, here, the possibility of receiving medication was,also, higher: 4.54 (Cl: 2.21-9.32). Furthermore, people who were smokers had a lower awareness. There was a significant increase in diabetes' control among people with secondary and high school education (2.4 (Cl: $0.92-$ 6.23).

Conclusions The current study demonstrated the increased prevalence of pre-/diabetes as well as low awareness, inadequate treatment and control. More effective and corrective factors in reducing the risk of diabetes and its control require more attention.

\section{Introduction}

Despite the current endeavors in the prevention and treatment of diabetes, it is still one of the most common chronic diseases and one of the leading cause of mortality, morbidity, and health system costs worldwide $(1,2)$. Diabetes affects quality of life and lifespan and is related to multiple complications, in particular, cardiovascular diseases such as myocardial infarction, stroke, and heart failure (3). In fact, diabetes, along with risk factors including obesity, high-blood pressure and dyslipidemia, increases the risk of cardiovascular disease significantly (1). Diabetes was responsible for over 5 million deaths that occurred in people aged 20 to 79 in 2015, among which more than 4 million were in low- and middle-income nations (4). The global prevalence of diabetes is rapidly increasing due to ageing, urbanisation, changes in lifestyle, industrialisation, and the increase in obesity (5). The pandemic effects of diabetes are not solely observed in industrialised countries, but also in developing counties (6). In 2016, WHO announced the number of individuals with diabetes as 422 million, which is predicted to escalate to 642 million in 2040 (7).

Among the seven WHO regions, the highest prevalence of diabetes is in the Eastern Mediterranean region, and it is expected to increase in the upcoming decades (8). Diabetes is a significant health concern in Iran; results of a recent systematic and meta-analysis showed a prevalence of $24 \%$ in people over 40 years (6).

Despite the advances in the diagnosis and treatment of diabetes, a large proportion of patients are still unaware of their disease. Awareness is an important part of behaviour change because when people are aware of their illness, they are more likely to participate in treatment and control programs (9). Epidemiological studies showed that early treatment and control of diabetes is necessary for prevention or delaying the complications $(10,11)$.

Nevertheless, the awareness, treatment, and control of diabetes is disproportionately low (12). According to a study carried out in seven nations, $24-62 \%$ of people were not aware of their illness and hence were not being treated. According to WHO studies in 11 countries, between $6 \%$ and $70 \%$ of the people whose blood glucose was tested, were diagnosed with diabetes and $4-66 \%$ of them were taking medication for their treatment (13). The undiagnosis of diabetes has significant implications for public health since these people are left without treatment and are at the higher risk of developing the complications of diabetes and, ultimately, at a higher risk of mortality $(14,15)$.

The aim of this study was to determine the prevalence of pre-/diabetes, awareness, treatment, and control of diabetes and its correlates among Azari people aged 35 years and older in the northwest of Iran participating in the pilot phase of Azar cohort study; a province level of the Prospective Epidemiological Research Studies of the Iranian Adults (PERSIAN) (16).

\section{Materials And Methods}

The PERSIAN study has been launched in October 2014 in different geographical regions of Iran $(n=18)$ which mainly aimed at assessing a comprehensive range of different biomarkers, clinical, lifestyle, and socioeconomic factors of common non-communicable diseases among 
Iranian adults (16).

The current study was based on the data from the pilot phase of the Azar cohort study which was conducted in Khamene city in East Azerbaijan province located in the Northwest of Iran. All individuals aged 35 years and older (1236) were invited to participate in the study. Of whom a total of 1038 subjects participated in the current study (participation rate $84 \%$ ) and were included in the analysis. The participants were invited to visit the Azar cohort centre located in Khamene city. A comprehensive questionnaire were completed by trained interviewers, and biological samples (urine, blood, hair and nail) were collected from all participants between October to December 2014. Lipid profiles, $\mathrm{HbA}_{1} \mathrm{C}$ and FBS were measured by an autoanalyzer (17).

Written informed consent was obtained from all participants of the study. This study also received approval from the Ethics Committee at Tabriz University of Medical Sciences (TBZMED.REC.1394.524).

\section{Definition of Variables}

Anthropometric measures were measured according to the standard protocol recommended by the PERSIAN guideline (16), the Body Mass Index (BMI) was calculated by dividing weight $(\mathrm{kg})$ by height in meters squared $\left(\mathrm{m}^{2}\right)$. Participants were divided, based on BMI, into normal groups (less than $25 \mathrm{~kg} / \mathrm{m} 2)$, overweight (25-29 /9 kg/m2), and obese (30 kg/m2 and more). The waist-to-hip ratio of higher or equal to 0.9 in males and 0.8 in females was accounted as their abdominal obesity $(18,19)$. The pattern of physical activity of subjects was determined using a physical-activity questionnaire, which consisted of 23 items and whose validity was confirmed by Cronbach's alpha of 0.7 (20). In this questionnaire, subjects reported their daily activities including rest and sleep as well as light and heavy activities based on hours and minutes. The metabolic equivalent (MET) classification was employed to calculate the intensity of physical activity. To determine each level of activities, the amount of MET was multiplied by the time assigned to each activity. The resulting figure represented the average level of physical activity on days of the week. The final MET-time was categorized as no physical activity (MET > 35.25) and as physical activity $(\mathrm{MET} \geq 35.25)(20,21)$.

Total Cholesterol (TC) $\geq 200 \mathrm{mg} / \mathrm{dl}$, Triglyceride (TG) $\geq 150 \mathrm{mg} / \mathrm{dl}$, and Low-Density Lipoprotein (LDL) $\geq 130 \mathrm{mg} / \mathrm{dl}$ classified as increased level of plasma lipids. In addition, a high-density lipoprotein (HDL) value of $\leq 40 \mathrm{mg} / \mathrm{dl}$ for males and $\leq 50 \mathrm{mg} / \mathrm{dl}$ for females defines as the abnormal level of plasma HDL-C (17). The presence of diabetes was defined as follows: $\mathrm{HbA}_{1} \mathrm{C}>6.4$ (mg/dl), FBS> 125 (mg/dl), or taking diabetes' medications or self-reporting of doctor-diagnosed diabetes. Certain individuals with $(5.7 \leq \mathrm{HbA} 1 \mathrm{C} \leq 6.4)$ or $(100 \leq \mathrm{FBS} \leq 125)$ were considered to be pre-diabetic. The awareness of having diabetes was defined as follows: The ratio of those subjects who stated that a physician had already diagnosed their disease to those who have diabetes. Among doctor-diagnosed people with diabetes, the treatment of diabetes was defined as those who were taking diabetes medications to all. Among those who were taking diabetes medicine; the control of diabetes was defined if $\mathrm{HbA} 1 \mathrm{C}<7.0(\mathrm{mg} / \mathrm{dl})(22)$.

Having cardiovascular diseases (ischemic heart disease, heart failure, stroke, hypertension), thyroid disease, musculoskeletal disorders (arthritis, osteoporosis), chronic lung disease (asthma, chronic pulmonary disease), cancer, kidney disease, psychological disorders (depression and other disorders) were considered as accompanying diseases. The latter was determined by clinical examinations carried out by physicians and the self-reports of subjects, and para-clinic, as well.

\section{Data Analysis}

Data was described using, mean, standard deviation (SD) for quantitative variables and frequency for qualitative variables. To investigate the association between demographic factors, lifestyle, metabolic and biomarker of the possibility of being diagnosed with diabetes, awareness, treatment and control of diabetes, univariate and multivariate logistic regression was used. The findings were reported as the odds ratio (OR) with $95 \%$ confidence intervals (Cl). The variables included in the model were: gender, marital status, education, age, body mass index, smoking, physical activity, high cholesterol, high triglycerides, abdominal obesity and associated disease. All analyses were performed using STATA (version 14), the statistical software.

\section{Results}

A total of 1,236 residents aged 35 and above in Khameneh city were invited to take a part in this study, with 1,038 ones agreeing to participate (83\% participation rate). The average and standard deviation of participants' age was $52 / 41 \pm 11 / 67$. The majority of them were females (54.5\%) and 912 participants (88.1\%) were married. 399 subjects had the elementary education or were illiterate; also, most of the subjects, 742 ones (71.5\%), were overweight or obese. The overall prevalence of diabetes and pre-diabetes was reported as $18.2 \%$ and $34.8 \%$, respectively. The prevalence of diabetes in males and females was similar. The prevalence of diabetes increased with age from $11.8 \%$ in the age group of $<50$ years to $29.8 \%$ in the age group of over 60 years. Furthermore, people with at least one disease were more likely to be 
diagnosed with diabetes ( $14.3 \%$ vs $23.5 \%)$. Also, subjects with abdominal obesity were more likely to have diabetes than others ( $24.9 \%$ vs 7.9\%) (Table 1). 
Table 1

General characteristics, diabetes prevalence, awareness, treatment and control among people 35 years and older, Pilot phase of AZAR cohort

\begin{tabular}{|c|c|c|c|c|c|c|}
\hline Variables & $N(\%)$ & $\begin{array}{l}\text { Diabetes } \\
\text { prevalence } \\
\mathbf{N}(\%) \text { of } \\
\text { total }\end{array}$ & $\begin{array}{l}\begin{array}{l}\text { Pre- } \\
\text { diabetes } \\
\text { prevalence }\end{array} \\
\mathrm{N}(\%) \text { of } \\
\text { total }\end{array}$ & $\begin{array}{l}\text { Awareness } \\
\text { N (\%) if } \\
\text { prevalent } \\
\text { cases }\end{array}$ & $\begin{array}{l}\text { Treatment } \\
\mathrm{N}(\%) \text { of } \\
\text { aware }\end{array}$ & $\begin{array}{l}\text { Control } \\
\text { N (\%) of aware }\end{array}$ \\
\hline Total & 1038(100) & 189(18.2) & & $103(65.2)$ & $74(44.3)$ & $38(40.9)$ \\
\hline \multicolumn{7}{|l|}{ Age (years) } \\
\hline$<50$ & $466(44.9)$ & $55(11.8)$ & & $28(66.7)$ & $22(39.3)$ & $8(30.8)$ \\
\hline $50-60$ & $354(34.1)$ & $69(19.5)$ & & $42(66.7)$ & $33(49.3)$ & $15(39.4)$ \\
\hline$>60$ & $218(21.0)$ & $65(29.8)$ & & $33(62.3)$ & $19(43.3)$ & $15(51.7)$ \\
\hline \multicolumn{7}{|l|}{ Sex } \\
\hline Male & $467(45.0)$ & $85(18.2)$ & & $45(60.0)$ & $28(34.6)$ & $17(44.7)$ \\
\hline Female & $571(55.0)$ & 104 (18.2) & & $58(69.9)$ & $46(53.5)$ & $21(38.2)$ \\
\hline \multicolumn{7}{|l|}{ Marital status } \\
\hline Married & $912(88.2)$ & $165(18.0)$ & & $92(65.7)$ & $64(43.0)$ & $33(40.7)$ \\
\hline Single/divorced/widow & $122(11.8)$ & $24(19.7)$ & & $11(61.1)$ & $10(55.6)$ & $5(41.7)$ \\
\hline \multicolumn{7}{|l|}{ Education } \\
\hline University & $263(25.4)$ & $42(19.0)$ & & $22(59.5)$ & $19(42.2)$ & $5(25.0)$ \\
\hline Secondary/high school & $374(36.0)$ & $56(15.0)$ & & $35(74.5)$ & $22(44.0)$ & $14(48.3)$ \\
\hline Illiterate/elementray & $401(38.6)$ & $91(22.7)$ & & $46(62.2)$ & $33(45.8)$ & $19(43.2)$ \\
\hline \multicolumn{7}{|l|}{ BMI(kg/m²) } \\
\hline Normal & $287(27.9)$ & $37(12.9)$ & & $19(63.3)$ & $14(48.3)$ & $9(45.0)$ \\
\hline Overweight & $426(41.5)$ & $71(16.7)$ & & $42(68.8)$ & $28(39.4)$ & $12(35.3)$ \\
\hline Obese & $314(30.6)$ & $79(25.2)$ & & $41(62.1)$ & $31(47.0)$ & $17(44.7)$ \\
\hline \multicolumn{7}{|l|}{ WHR (Waist to Hip Ratio) } \\
\hline Normal & $403(42.5)$ & $32(7.9)$ & & $19(76.0)$ & $16(48.5)$ & $8(42.1)$ \\
\hline Abnormal & $546(57.5)$ & $133(24.4)$ & & $72(64.3)$ & $51(43.2)$ & $20(33.3)$ \\
\hline Hypercholestrolemia (Yes) & $357(34.8)$ & $60(16.8)$ & & $30(63.8)$ & $18(33.33)$ & $6(30.00)$ \\
\hline Hypertriglisiridemia (Yes) & $430(41.9)$ & $106(24.6)$ & & $61(67.8)$ & $42(46.7)$ & $17(33.3)$ \\
\hline Comorbidity (Yes) & $424(40.9)$ & $100(23.6)$ & & $69(78.4)$ & $49(60.5)$ & $23(38.3)$ \\
\hline Smoking (Yes) & $161(17.0)$ & $25(15.5)$ & & $14(63.6)$ & $9(36.0)$ & $5(45.5)$ \\
\hline \multicolumn{7}{|l|}{ Physical activity (MET-Time) } \\
\hline No active & $477(50.1)$ & $86(18.0)$ & & $52(72.2)$ & $37(46.8)$ & $17(36.2)$ \\
\hline Active & 475 (49.9) & 79 (16.6) & & $39(60.0)$ & $30(41.7)$ & $11(34.4)$ \\
\hline Diabetes & & Awareness & & Treatment & & Control \\
\hline $\begin{array}{l}\text { Sociodemographic } \\
\text { variables }\end{array}$ & $\begin{array}{l}\mathrm{OR}^{2} \\
(95 \% \mathrm{Cl})\end{array}$ & $\begin{array}{l}\mathrm{OR}^{1} \\
(95 \% \mathrm{Cl})\end{array}$ & $\begin{array}{l}\mathrm{OR}^{3} \\
(95 \% \mathrm{Cl})\end{array}$ & $\begin{array}{l}\mathrm{OR}^{1} \\
(95 \% \mathrm{Cl})\end{array}$ & $\begin{array}{l}\mathrm{OR}^{4} \\
(95 \% \mathrm{Cl})\end{array}$ & $\begin{array}{l}\mathrm{OR}^{1} \\
(95 \% \mathrm{Cl})\end{array}$ \\
\hline \multicolumn{7}{|l|}{ Age $($ ref $<50)$} \\
\hline Groups (years) & & & & & & \\
\hline
\end{tabular}




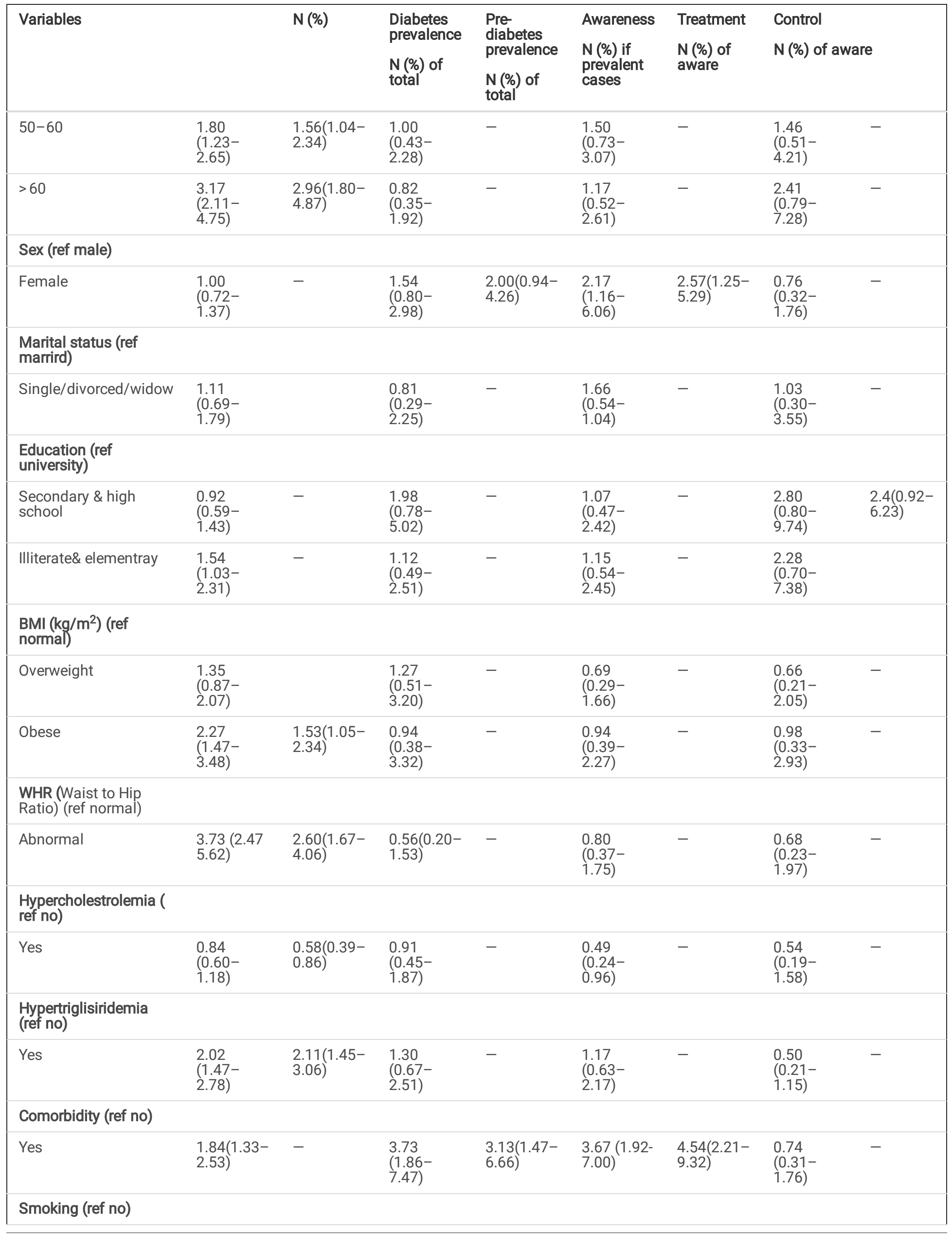




\begin{tabular}{|c|c|c|c|c|c|c|c|c|}
\hline \multirow[t]{2}{*}{ Variables } & & \multirow[t]{2}{*}{$\mathrm{N}(\%)$} & \multirow{2}{*}{$\begin{array}{l}\text { Diabetes } \\
\text { prevalence } \\
\mathrm{N}(\%) \text { of } \\
\text { total }\end{array}$} & \multirow{2}{*}{$\begin{array}{l}\text { Pre- } \\
\text { diabetes } \\
\text { prevalence } \\
\mathrm{N}(\%) \text { of } \\
\text { total }\end{array}$} & \multirow{2}{*}{$\begin{array}{l}\text { Awareness } \\
\mathrm{N}(\%) \text { if } \\
\text { prevalent } \\
\text { cases }\end{array}$} & \multirow{2}{*}{$\begin{array}{l}\text { Treatment } \\
\mathrm{N}(\%) \text { of } \\
\text { aware }\end{array}$} & \multirow{2}{*}{\multicolumn{2}{|c|}{$\begin{array}{l}\text { Control } \\
N(\%) \text { of aware }\end{array}$}} \\
\hline & & & & & & & & \\
\hline Yes & $\begin{array}{l}0.84 \\
(0.53- \\
1.35)\end{array}$ & - & $\begin{array}{l}0.86 \\
(0.33- \\
2.23)\end{array}$ & - & $\begin{array}{l}0.65 \\
(0.27- \\
1.60)\end{array}$ & - & $\begin{array}{l}1.63 \\
(0.44- \\
5.91)\end{array}$ & - \\
\hline \multicolumn{9}{|c|}{$\begin{array}{l}\text { Physical activity (MET- } \\
\text { Time) (ref no active) }\end{array}$} \\
\hline Active & $\begin{array}{l}1.02 \\
(0.71- \\
1.46)\end{array}$ & - & $\begin{array}{l}0.57 \\
(0.28- \\
1.18)\end{array}$ & - & $\begin{array}{l}0.81 \\
(0.42- \\
1.54)\end{array}$ & - & $\begin{array}{l}0.92(0.36- \\
2.36)\end{array}$ & - \\
\hline
\end{tabular}

\section{Table 1. ABOUT HERE}

$65.1 \%$ of those with diabetes were aware of their disease. Males were less likely, compared to females, to be aware of their illness ( $60 \%$ vs $69.8 \%$ ). Also, subjects over the age of 60 years had lower awareness rates compared to other participants (62.2\% vs $66.6 \%)$. The awareness percentage of those with at least one comorbid condition was higher than those who had no other illness ( $78.4 \%$ vs $49.2 \%)$. Also, 44.3 percent of those diagnosed with diabetes were receiving treatment, which was lower in the age groups of under 50 years old, in men, married and overweight people. Among participants with diabetes who were taking the medicine, only $40.8 \%$ of them had controlled blood glucose. Controlled blood glucose was higher in males compared to females (44.7\% vs $38.1 \%)$. Moreover, the age group of under 50 years old had the lowest percentage of blood glucose control than other age groups (30.7\%) (Fig. 1).

\section{Figure 1. ABOUT HERE}

According to the regression model, participants with at least one comorbid condition were more aware of having diabetes 3.73 (Cl: 1.86 7.47). The variables of sex, high-blood pressure and high cholesterol were associated with receiving diabetes' medications. Women were two times more likely to receive diabetes medication 2.17 (Cl: 1.16-6.06). However, high cholesterol diminished this chance (0.49 (Cl: 0.24-0.96)). Although diabetes control was lower among those with abdominal obesity, having other medical conditions and high triglyceride content reduced the chance of controlling diabetes. This however, was not significant.

Ultimately, to identify the effective factors and, also, to control the confounding factors, the variables were introduced step by step into the multivariate regression model. Increasing age was one of the factors related to an increased frequency of diabetes so that in the age group of 50-60 years, the possibility of having diabetes was 1.56 (Cl: 1.04-2.34) times higher than the younger age group; In the age group of over 60 years, it was 2.96 (Cl: 1.80-4.87) higher. Furthermore, the prevalence of diabetes in people with abdominal obesity was 2.60 (Cl: 1.67-4.06) higher than those with standard measures. Females had a better awareness of their disease compared to males (2.00 (Cl: 0.94-4.26)), and their reception of diabetes' medicines was higher: 2.57 (Cl: 1.25-5.29). Having at least one comorbid condition was associated with an increased awareness of diabetes (3.13 (Cl: 1.47-6.66)); Here the possibility of receiving medication was also higher: 4.54 (Cl: 2.21-9.32). Additionally, people who were smokers had a lower awareness of disease, although this relationship was not statistically significant. Results showed a significant increase in diabetes' control among people with secondary and high school education (2.4 (Cl: 0.92-6.23).

Table 2. Risk factors analyses on the prevalence, awareness, treatment and control of diabetes among 35 years and older in Khameneh

OR1: Crude Odds Ratio OR2 : Odds Ratio adjusted for sex, marital status, education, comorbidity, smoking, physical activity OR3-4 : Odds Ratio adjusted for age, marital status, education, BMI, WHR, hyperlipidemia, smoking, physical activity OR5 : Odds Ratio adjusted for sex, age, marital status, BMI, WHR, hyperlipidemia, smoking, physical activity, comorbidity 


\begin{tabular}{|c|c|c|c|c|c|c|c|c|}
\hline \multirow{2}{*}{$\begin{array}{l}\text { Variables } \\
\text { Sociodemographic variables }\end{array}$} & \multicolumn{2}{|l|}{ Diabetes } & \multicolumn{2}{|l|}{ Awareness } & \multicolumn{2}{|l|}{ Treatment } & \multicolumn{2}{|l|}{ Control } \\
\hline & $\mathrm{OR}^{1}(95 \% \mathrm{CI})$ & $\mathrm{OR}^{2}(95 \% \mathrm{CI})$ & $\mathrm{OR}^{1}(95 \% \mathrm{CI})$ & $\mathrm{OR}^{3}(95 \% \mathrm{CI})$ & $\mathrm{OR}^{1}(95 \% \mathrm{CI})$ & $\mathrm{OR}^{4}(95 \% \mathrm{CI})$ & $\mathrm{OR}^{1}(95 \% \mathrm{CI})$ & $\mathrm{OR}^{5}(95 \% \mathrm{CI})$ \\
\hline \multicolumn{9}{|l|}{$\begin{array}{l}\text { Age (ref<50) } \\
\text { Groups (years) }\end{array}$} \\
\hline $50-60$ & $1.80(1.23-2.65)$ & $1.56(1.04-2.34)$ & $1.00(0.43-2.28)$ & - & $1.50(0.73-3.07)$ & - & $1.46(0.51-4.21)$ & - \\
\hline$>60$ & $3.17(2.11-4.75)$ & $2.96(1.80-4.87)$ & $0.82(0.35-1.92)$ & - & $1.17(0.52-2.61)$ & - & $2.41(0.79-7.28)$ & - \\
\hline \multicolumn{9}{|l|}{ Sex (ref male) } \\
\hline Female & $1.00(0.72-1.37)$ & - & $1.54(0.80-2.98)$ & $2.00(0.94-4.26)$ & $2.17(1.16-6.06)$ & $2.57(1.25-5.29)$ & $0.76(0.32-1.76)$ & - \\
\hline \multicolumn{9}{|l|}{ Marital status (ref marrird) } \\
\hline Single/divorced/widow & $1.11(0.69-1.79)$ & & $0.81(0.29-2.25)$ & - & $1.66(0.54-1.04)$ & - & $1.03(0.30-3.55)$ & - \\
\hline \multicolumn{9}{|l|}{ Education (ref university) } \\
\hline Secondary \& high school & $0.92(0.59-1.43)$ & - & $1.98(0.78-5.02)$ & - & $1.07(0.47-2.42)$ & - & $2.80(0.80-9.74)$ & $2.4(0.92-6.23)$ \\
\hline Illiterate\& elementray & $1.54(1.03-2.31)$ & - & $1.12(0.49-2.51)$ & - & $1.15(0.54-2.45)$ & - & $2.28(0.70-7.38)$ & \\
\hline \multicolumn{9}{|l|}{ BMI $\left(\mathrm{kg} / \mathrm{m}^{2}\right)$ (ref normal) } \\
\hline Overweight & $1.35(0.87-2.07)$ & & $1.27(0.51-3.20)$ & - & $0.69(0.29-1.66)$ & - & $0.66(0.21-2.05)$ & - \\
\hline Obese & $2.27(1.47-3.48)$ & $1.53(1.05-2.34)$ & $0.94(0.38-3.32)$ & - & $0.94(0.39-2.27)$ & - & $0.98(0.33-2.93)$ & - \\
\hline \multicolumn{9}{|l|}{ WHR (Waist to Hip Ratio) (ref normal) } \\
\hline Abnormal & $3.73(2.475 .62)$ & $2.60(1.67-4.06)$ & $0.56(0.20-1.53)$ & - & $0.80(0.37-1.75)$ & - & $0.68(0.23-1.97)$ & - \\
\hline \multicolumn{9}{|l|}{ Hypercholestrolemia ( ref no) } \\
\hline Yes & $0.84(0.60-1.18)$ & $0.58(0.39-0.86)$ & $0.91(0.45-1.87)$ & - & $0.49(0.24-0.96)$ & - & $0.54(0.19-1.58)$ & - \\
\hline \multicolumn{9}{|l|}{ Hypertriglisiridemia (ref no) } \\
\hline Yes & $2.02(1.47-2.78)$ & $2.11(1.45-3.06)$ & $1.30(0.67-2.51)$ & - & $1.17(0.63-2.17)$ & - & $0.50(0.21-1.15)$ & - \\
\hline \multicolumn{9}{|l|}{ Comorbidity (ref no) } \\
\hline Yes & $1.84(1.33-2.53)$ & - & $3.73(1.86-7.47)$ & $3.13(1.47-6.66)$ & $3.67(1.92-7.00)$ & $4.54(2.21-9.32)$ & $0.74(0.31-1.76)$ & - \\
\hline \multicolumn{9}{|l|}{ Smoking (ref no) } \\
\hline Yes & $0.84(0.53-1.35)$ & - & $0.86(0.33-2.23)$ & - & $0.65(0.27-1.60)$ & - & $1.63(0.44-5.91)$ & - \\
\hline \multicolumn{9}{|l|}{ Physical activity (MET-Time) (ref no active) } \\
\hline Active & $1.02(0.71-1.46)$ & - & $0.57(0.28-1.18)$ & - & $0.81(0.42-1.54)$ & - & $0.92(0.36-2.36)$ & - \\
\hline
\end{tabular}

The aim of this study was to determine the prevalence of diabetes, pre-diabetes, awareness, treatment, disease control and the related factors on diabetes in people over 35 years old in the pilot phase of Azar cohort study in the Northwest of Iran. In this study, the overall prevalence of diabetes and pre-diabetes were $18.2 \%$ and $34.8 \%$, respectively.

The prevalence of diabetes in the current study (18.2\%) was much higher than its prevalence (8.8\%) in the world and (23) $10.7 \%$ in the MENA region in 2015 (24). In Iran, some studies have been consistent with the present study. In a study carried out by Lotfi et al. in the Iranian city of Yazd in 2012, the prevalence of diabetes was reported as $16.3 \%$ and close to the results of the present study (25). However, according to studies conducted in Gilan and Fars Provinces in Iran, the prevalence of diabetes was reported as $12.4 \%$ and $14.1 \%$, respectively, figures lower than our study's estimate $(26,27)$. This difference might be due to the difference between the age groups of participants in these studies as well as different criteria that may have been utilized for diagnosing diabetes. The majority of these studies have not used $\mathrm{HbA}_{1} \mathrm{C}$ to diagnose diabetes.

With the increase of age, the prevalence of diabetes significantly augmented. The present study's findings are consistent with those in the studies carried out in other parts of Iran (27-29) as well as in other countries (30-33). This signifies the importance of paying attention to diabetes in countries like Iran, whose populations are ageing.

Obesity, abdominal obesity and high triglyceride content had a significant association with the increased prevalence of diabetes, which is accordant with other studies $(12,30,33,34)$.

The subjects' awareness of having diabetes was $58.4 \%$. In a study conducted by Amiri in the North of Iran, $78.3 \%$ of people were aware of their disease, a percentage higher than that obtained in our study (27). In Shirani's study in the City of Isfahan, $54.6 \%$ of people (35) and in Yazdan Panah's study in City of Ahwaz, 40.4\% people were aware of their disease (29). The percentage of awareness in the MENA region in middle-income nations was $50 \%$ and $40.7 \%$ in low-income countries (24). The findings of other studies carried out in other nations are also consistent with the results of the present study $(12,36,37)$. The reasons for a higher level of awareness in the present study might be attributed to higher level of education in the studied population and accessible health care services as well.

The percentage of females' awareness was significantly higher compared to males, which is agreeing with the results of other studies $(12,27$, 30). This increased awareness may be due to the higher interest and attention of females to their health conditions. Subjects with the minimum of one disease were $3.13(1.47-6.66)$ times more aware of having diabetes compared to others; these results are consistent with the findings in studies performed in Switzerland (36) and Ahwaz (29). Furthermore, people who were smokers had lower awareness, although this relationship was not statistically significant. Studies carried out in China (32) and Malaysia (38) confirm the findings of the present study.

Among the known cases of having diabetes, $44.3 \%$ were receiving treatment, a figure that is less than $79.7 \%$ of Mohtasham's study in North of Iran (27) and other countries $(30,32,36,37)$. As women were significantly more aware of their disease, they were taking drugs more than men. The findings of studies conducted in Iran $(27)$ and China confirm this issue $(32,37)$.

This study features many advantages. Firstly, it is a population-based study including all people over 35 years of age. Secondly, unlike other studies that estimated the prevalence of diabetes is solely based on FBS or the consumption of diabetes' medications and people's selfreports, this study has adopted $\mathrm{HbA}_{1} \mathrm{C}$ alongside other items to determine the prevalence of diabetes. Thirdly, in this study, standard 
questionnaires as well as trained interviewers, who were carefully supervised, were constructed and utilized to collect data to confirm the accuracy of measured data. The main weakness of this study was the lack of examining nutritional conditions and economic status of individuals, pivotal factors affecting people's affliction, awareness, and the treatment and control of diabetes.

\section{Conclusion}

The current study demonstrated the increased prevalence of diabetes, pre-diabetes as well as low awareness, inadequate treatment and control among people with diabetes in Khameneh city. It seems that there is more attention required in the policy construction for the prevention of diabetes, treatment and control of diabetes and effective and corrective factors in reducing the risk of diabetes. On the other hand, the lack of awareness of having diabetes may lead to intensified complications. Here, increased health education, as well as improved screening programs, can lead to people's increased awareness of their disease.

\section{Abbreviations}

DM: Diabetes Mellitus; $\mathrm{HbA}_{1} \mathrm{C}$ : Hemoglobin $\mathrm{A}_{1} \mathrm{C}$; FBS: Fasting Blood Sugar; BMI: Body Mass Index; MET: Metabolic Equivalent; TC: Total Cholesterol; TG: Triglyceride; SD: Standard Deviation; OR: Odds Ratio; Cl: Confidence Intervals;

\section{Declarations}

\section{Acknowledgements}

This research project was approved by the Tabriz University of Medical Sciences research comittee. The authors appreciated the respected authorities and all colleagues and people participating in this study. We also would like to acknowledge Seyed Erfan Shamshirgaran for her contribution to the data management and manuscript editing.

\section{Authors' contributions区}

All authors were involved in design of the protocol and preparation of the Human Research Ethics Committee application. ZG and SMS were responsible for data analysis and the preparation of drafts for the manuscript. SMS, NA, PS and FN supervised and supported data analysis and contributed to all drafts of the manuscript.

\section{Funding}

This research project was sponsored by the Health Sciences Faculty of Tabriz University of Medical Sciences.

\section{Availability of data and materials}

The data generated during this study is available from the corresponding author upon request.

\section{Ethics approval and consent to participate}

This study received ethical approval from the Tabriz University of Medical Sciences Research Ethics Committee (TBZMED.REC.1394.524). Written informed consent was also obtained from all participants of study.

\section{Consent for publication}

Not applicable.

\section{Conflict of Interest}

Authors have no conflict of interest to declare

\section{References}

1. Aguayo A, Urrutia I, Gonzalez-Frutos T, Martinez R, Martinez-Indart L, Castano L, et al. Prevalence of diabetes mellitus and impaired glucose metabolism in the adult population of the Basque Country, Spain. Diabetic medicine: Journal of the British Diabetic Association. 2017;34(5):662-6. 
2. Collaboration NRF. Worldwide trends in diabetes since 1980: a pooled analysis of 751 population-based studies with $4 \cdot 4$ million participants. The Lancet. 2016;387(10027):1513-30.

3. Rosella LC, Lebenbaum M, Fitzpatrick T, O'Reilly D, Wang J, Booth GL, et al. Impact of diabetes on healthcare costs in a population-based cohort: a cost analysis. Diabetic medicine: Journal of the British Diabetic Association. 2016;33(3):395-403.

4. Ogurtsova K, da Rocha Fernandes JD, Huang Y, Linnenkamp U, Guariguata L, Cho NH, et al. IDF Diabetes Atlas: Global estimates for the prevalence of diabetes for 2015 and 2040. Diabetes Res Clin Pract. 2017;128:40-50.

5. Ebrahimi H, Emamian MH, Shariati M, Hashemi H, Fotouhi A. Diabetes mellitus and its risk factors among a middle-aged population of Iran, a population-based study. International Journal of Diabetes in Developing Countries. 2016;36(2):189-96.

6. Haghdoost AA, Rezazadeh-Kermani M, Sadghirad B, Baradaran HR. Prevalence of type 2 diabetes in the Islamic Republic of Iran: systematic review and meta-analysis. Eastern Mediterranean Health Journal. 2009;15(3):591-9.

7. World Health Organization Media Centre. Diabetes Fact Sheet, 2016 [cited 201629 April]; Available from: http://www.who.int/mediacentre/factsheets/fs312/en/.

8. Moradi-Lakeh M, Forouzanfar MH, El Bcheraoui C, Daoud F, Afshin A, Hanson SW, et al. High Fasting Plasma Glucose, Diabetes, and Its Risk Factors in the Eastern Mediterranean Region, 1990-2013: Findings From the Global Burden of Disease Study 2013. Diabetes care. 2017;40(1):22-9.

9. Ruhembe CC, Mosha TC, Nyaruhucha CN. Prevalence and awareness of type 2 diabetes mellitus among adult population in Mwanza city, Tanzania. Tanzan J Health Res. 2014;16(2):89-97.

10. Hasan R, Firwana B, Elraiyah T, Domecq JP, Prutsky G, Nabhan M, et al. A systematic review and meta-analysis of glycemic control for the prevention of diabetic foot syndrome. Journal of vascular surgery. 2016;63(2 Suppl):22S-8S.e1-2.

11. Menezes MM, Lopes CT, Nogueira Lde S. Impact of educational interventions in reducing diabetic complications: a systematic review. Revista brasileira de enfermagem. 2016;69(4):773-84.

12. Liu X, Li Y, Li L, Zhang L, Ren Y, Zhou H, et al. Prevalence, awareness, treatment, control of type 2 diabetes mellitus and risk factors in Chinese rural population: the RuralDiab study. Sci Rep. 2016;6:31426.

13. Organization WH. Tracking universal health coverage: first global monitoring report: World Health Organization; 2015.

14. Bener A, Zirie M, Janahi IM, Al-Hamaq AO, Musallam M, Wareham NJ. Prevalence of diagnosed and undiagnosed diabetes mellitus and its risk factors in a population-based study of Qatar. Diabetes Res Clin Pract. 2009;84(1):99-106.

15. Setji T, Hopkins TJ, Jimenez M, Manning E, Shaughnessy M, Schroeder R, et al. Rationalization, Development, and Implementation of a Preoperative Diabetes Optimization Program Designed to Improve Perioperative Outcomes and Reduce Cost. Diabetes spectrum : a publication of the American Diabetes Association. 2017;30(3):217-23.

16. Poustchi H, Eghtesad S, Kamangar F, Etemadi A, Keshtkar AA, Hekmatdoost A, et al. Prospective Epidemiological Research Studies in Iran (the PERSIAN Cohort Study): Rationale, Objectives, and Design. Am J Epidemiol. 2018;187(4):647-55.

17. Jellinger PS, Smith DA, Mehta AE, Ganda O, Handelsman Y, Rodbard HW, et al. American Association of Clinical Endocrinologists' Guidelines for Management of Dyslipidemia and Prevention of Atherosclerosis: executive summary. Endocrine practice : official journal of the American College of Endocrinology and the American Association of Clinical Endocrinologists. 2012;18(2):269-93.

18. World Health Organization Physical Status. The use and interpretation of anthropometry. Geneva CH, WHO 1995 , technical report 854.

19. Organization WH. Waist circumference and waist-hip ratio: report of a WHO expert consultation, Geneva, 8-11 December 2008. 2011.

20. Mirzaei M, Asghari-Jafarabadi M, Amini-Sani N, Bakhtari-Aghdam F, Dastgiri S. Psychometric evaluation of a self-reported physical activity questionnarie used in the pilot phase of the AZAR Cohort Study. Health Promot Perspect. 2016;6(3):152-8.

21. Aadahl M, Jorgensen T. Validation of a new self-report instrument for measuring physical activity. Med Sci Sports Exerc. 2003;35(7):1196-202.

22. Association AD. Standards of medical care in diabetes -2015 abridged for primary care providers. Clinical diabetes: a publication of the American Diabetes Association. 2015;33(2):97.

23. Organization WH. Global report on diabetes: World Health Organization; 2016.

24. Majeed A, El-Sayed AA, Khoja T, Alshamsan R, Millett C, Rawaf S. Diabetes in the Middle-East and North Africa: an update. Diabetes Res Clin Pract. 2014;103(2):218-22.

25. Lotfi MH, Saadati H, Afzali M. Prevalence of diabetes in people aged $\geq 30$ years: the results of screen-ing program of Yazd Province, Iran, in 2012. Journal of research in health sciences. 2013;14(1):88-92.

26. Bagheri P. The comparison of prevalence of diabete and hypertension between rural areas of fars and rural area of emro region. Iranian Journal of Endocrinology and Metabolism. 2011;13(2):157-64. 
27. Mohtasham-Amiri Z, Barzigar A, Kolamroudi HR, Hoseini S, Rezvani S, Shakib RJ, et al. Prevalence, awareness and control of diabetes in urban area of north of Iran, 2009. International Journal of Diabetes in Developing Countries. 2015;35(3):346-50.

28. MERACI M, FEIZI A, BAGHER NM. Investigating the prevalence of high blood pressure, type 2 diabetes mellitus and related risk factors according to a large general study in Isfahan-using multivariate logistic regression model. 2012.

29. Yazdanpanah L, Shahbazian HB, Moravej Aleali A, Jahanshahi A, Ghanbari S, Latifi SM. Prevalence, awareness and risk factors of diabetes in Ahvaz (South West of Iran). Diabetes \& metabolic syndrome. 2016;10(2 Suppl 1):S114-8.

30. Irazola V, Rubinstein A, Bazzano L, Calandrelli M, Chung-Shiuan C, Elorriaga N, et al. Prevalence, awareness, treatment and control of diabetes and impaired fasting glucose in the Southern Cone of Latin America. PLoS One. 2017;12(9):e0183953.

31. Jayawardena R, Ranasinghe P, Byrne NM, Soares MJ, Katulanda P, Hills AP. Prevalence and trends of the diabetes epidemic in South Asia: a systematic review and meta-analysis. BMC Public Health. 2012;12:380.

32. Yue J, Mao X, Xu K, Lu L, Liu S, Chen F, et al. Prevalence, Awareness, Treatment and Control of Diabetes Mellitus in a Chinese Population. PLoS One. 2016;11(4):e0153791.

33. Zhou X, Guan H, Zheng L, Li Z, Guo X, Yang H, et al. Prevalence and awareness of diabetes mellitus among a rural population in China: results from Liaoning Province. Diabetic medicine : a journal of the British Diabetic Association. 2015;32(3):332-42.

34. Yang F, Qian D, Chen J, Hu D, Hou M, Chen S, et al. Prevalence, awareness, treatment and control of diabetes mellitus in rural China: results from Shandong Province. Diabetic medicine : a journal of the British Diabetic Association. 2016;33(4):454-8.

35. Shirani S, Kelishadi R, Sarrafzadegan N, Khosravi A, Sadri G, Amani A, et al. Awareness, treatment and control of hypertension, dyslipidaemia and diabetes mellitus in an Iranian population: the IHHP study. Eastern Mediterranean health journal = La revue de sante de la Mediterranee orientale = al-Majallah al-sihhiyah li-sharq al-mutawassit. 2009;15(6):1455-63.

36. Kaiser A, Vollenweider P, Waeber G, Marques-Vidal P. Prevalence, awareness and treatment of type 2 diabetes mellitus in Switzerland: the CoLaus study. Diabetic medicine : a journal of the British Diabetic Association. 2012;29(2):190-7.

37. Wang C, Yu Y, Zhang X, Li Y, Kou C, Li B, et al. Awareness, treatment, control of diabetes mellitus and the risk factors: survey results from northeast China. PLoS One. 2014;9(7):e103594.

38. Yen ST, Tan AKG, Mustapha FI. Awareness of diabetes, hypertension, and hypercholesterolemia in Malaysia. J Diabetes. 2017;9(9):87483.

\section{Figures}
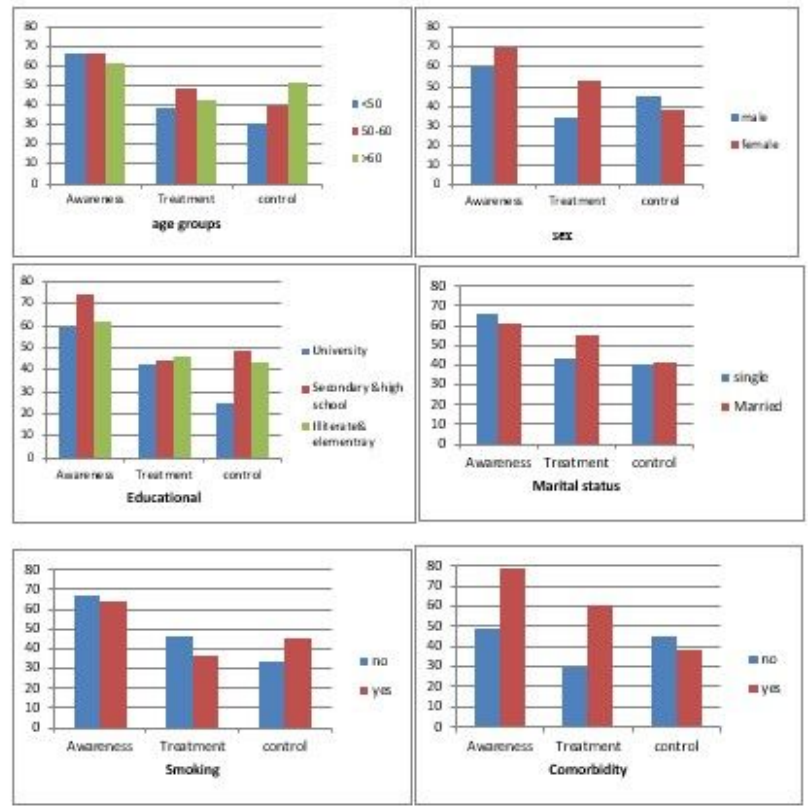

\section{Figure 1}

proportion of awareness, treatment and control of diabetes by subgroups of sex, age groups, Marital status, Educational, Comorbidity and Smoking 